\title{
Experimental Study of Relationship between Arc Light Intensity and Temperature in Low Voltage Switching Devices
}

\author{
Dongkyu Shin, Thomas G. Bull, and John W. McBride
}

\begin{abstract}
Arc motion in a quenching chamber has a significant influence on switching performance in a low voltage switching device (LVSD). A high-speed optical arc imaging system (AIS) has been used to investigate the influence of the design parameters of a quenching chamber on arc motion. Arc light intensity is transmitted to the photodiodes of the AIS through optical fibres during the switching process. The AIS and associated software enable the detailed arc motion to be tracked inside the chamber at an image sampling rate of $1 \mathrm{MHz}$.

Since higher arc temperature leads to greater radiation, it is assumed that the arc light intensity measured by the AIS is related to the arc temperature. However, there has been little empirical study of the correlation between the arc temperature and light intensity measured by the AIS.

In this paper, the relationship between the arc temperature and light intensity is investigated by measuring arc spectra and arc images. Arc spectra are captured by a spectrometer when the arc is ignited by copper wire in a narrow enclosed chamber and they are used to calculate the arc temperature by the Boltzmann plot method. At the same time, the AIS records the arc images from points adjacent to the fibre of the arc spectrometer. It is found that the arc light intensity measured by the AIS is directly related to the arc temperature; the correlation between the fourth power of temperature and the light intensity is an approximately linear trend.
\end{abstract}

Index Terms - Arc imaging system (AIS), arc light intensity, arc spectrum, arc temperature, Boltzmann plot method.

\section{INTRODUCTION}

L OW voltage switching devices (LVSDs) are widely used in $\checkmark$ power distribution networks to control electrical circuits under the normal condition and to protect humans and connected electrical equipment against overload or short circuit accidents. A quenching chamber is the main volume for current switching in an LVSD, which consists of a movable and fixed contact, arc runner, splitter plates, and vents. When the movable contact separates from the fixed contact under the condition of current flowing, an arc forms in the contact gap

D. Shin is with the Low Voltage Circuit Breaker Development Department, Hyundai Electric \& Energy system, 17-10, 240 beon-gil, Mabuk-ro, Giheung-gu, Yongin-si, Gyeongi-do 16891, Korea. (e-mail: ds7g14@ gmail.com).

T. G. Bull and J. W. McBride are with the Faculty of Engineering and the Environment, University of Southampton, Southampton, SO17 1BJ, U.K. and it moves towards the splitter plates by the combination of pressure gradient and Lorentz forces. As the arc moves towards the plates, it elongates, and, in the region of splitter plates, it is split into multiple arc segments, leading to an increase in the arc voltage. During the switching process of LVSDs, the successful arc interruption is strongly dependent on the arc motion inside the quenching chamber; therefore, investigating arc motion is fundamental to evaluate and predict LVSD switching performance [1] - [3].

To identify the chamber parameters that significantly influence arc motion, previous investigations have used high-speed camera, magnetic sensors, or optical fibre imaging systems. Using a high-speed camera (several tens of $\mathrm{kHz}$ ) requires the removal of a large section of the sidewall to image the arc within the quenching chamber [4]. This is a significant modification of the quenching chamber and may lead to a different interruption performance when compared with the original device. Detecting and tracking the magnetic field motion can provide the arc location and motion [5]; however, the calculated arc image is too simplistic and it is distorted by the ferromagnetic materials within the quenching chamber. Therefore, magnetic sensors have been used to a limited extent for the investigation of arc motion. An optical fibre arc imaging system (AIS) can obtain detailed arc motion at a high scanning rate (up to $6 \mathrm{MHz}$ ) without distortion and minimal modification required to the quenching chamber [6].

McBride et al. investigated the influence of several parameters on arc motion by the AIS [7] - [9]. It was found that the contact opening velocity, vent size, air volume behind the movable contact, arc current, and steel plates behind the arc runner have a significant effect on arc motion, while the contact material and polarity have a minimal influence. Chen et al. studied the correlation between arc motion and re-ignition in a magnetic contactor by using optical fibre arc imaging technology [10]. It was observed that arc motion greatly influences the probability of re-ignition; the better arc entry into the splitter plates leads to a reduction in the re-ignition probability. Shin et al. developed arc modelling to predict arc characteristics, based on magnetohydrodynamic theory, with special attention given to the Lorentz force acting on the arc column and the arc root area on the splitter plate [11] - [12]. Arc images measured by the AIS were compared with the simulated temperature distribution to validate the model.

Optical fibres, fixed in the sidewall of the quenching chamber, 
transmit the arc light intensity to the AIS as the arc propagates through the chamber. By capturing the light intensity, the AIS enables detailed tracking of the arc position during the interruption process. We assume that light intensity is related to the arc temperature since higher temperature leads to greater radiation (higher photon emission energy) [13]; however, there has been little empirical study of the relationship between arc temperature and light intensity measured by the AIS even though the AIS is widely used to investigate the arc motion in an LVSD chamber.

Apart from the investigation of arc motion by the AIS, there have been some experimental studies on the relationship between the current and air arc temperature. Takeuch et al. showed the distributions of Ag I spectra along the axis of an air arc column between Ag contacts. Using the relative intensities of Ag I spectra, they obtained an arc temperature of around $7000 \mathrm{~K}$ under conditions of $50 \mathrm{~V}$ DC supply voltage and $3.3 \mathrm{~A}$ current [14]. Jones et al. measured the temperature of the wall-stabilized air arc through the shock wave technique [15]. They presented the temperature distribution associated with the current value; the temperature of the cylindrical air arc of 10 $\mathrm{mm}$ in diameter is estimated at $12600 \mathrm{~K}$ at $60 \mathrm{~A}$ and $14200 \mathrm{~K}$ at $100 \mathrm{~A}$ current. Slade et al. investigated the air arc temperature in a $9.6 \mathrm{~mm}$ gap through the absolute values of $\mathrm{N}$ II spectra [16]. They found that the arc temperature is in the range of $20000 \mathrm{~K}$ to $23000 \mathrm{~K}$ when an 1100 A peak AC current flows through a free-burning arc.

In this paper, the arc spectrum and light intensity are measured simultaneously using a spectrometer and AIS, to investigate the correlation between the arc temperature and light intensity (AIS data). The arc temperature is calculated by the relative intensity of $\mathrm{Cu}$ I spectra when the arc is ignited by copper wire in a narrow enclosed chamber. The arc temperature obtained by spectroscopy analysis from this study is validated against other experimentally obtained data. Finally, a detailed comparison between the arc temperature and light intensity measured by the AIS is then presented.

\section{EXPERIMENTAL METHODS}

The light intensity and spectra of the arc are measured by the AIS and spectrometer, respectively. The measurement is taken when the half-cycle wave of the current flows through the chamber, at the location where the thin copper wire ignites the arc.

\section{A. Overall Set-up}

The discharge of a capacitor bank provides the current source to the experimental LVSD. The arc light is transmitted from the LVSD quenching chamber to the AIS and spectrometer by an array of optical fibres. Figure 1 shows a schematic arrangement for the arc imaging and spectra measurement. A single optical fibre is connected to the spectrometer and other fibres are linked to the AIS. The spectrometer is configured by the software (Ocean Insight, OceanView [17]) installed on a laptop computer that is also used to download the spectra data. The integration period (photon sampling duration) and the sampling frequency can be adjusted through the software. The

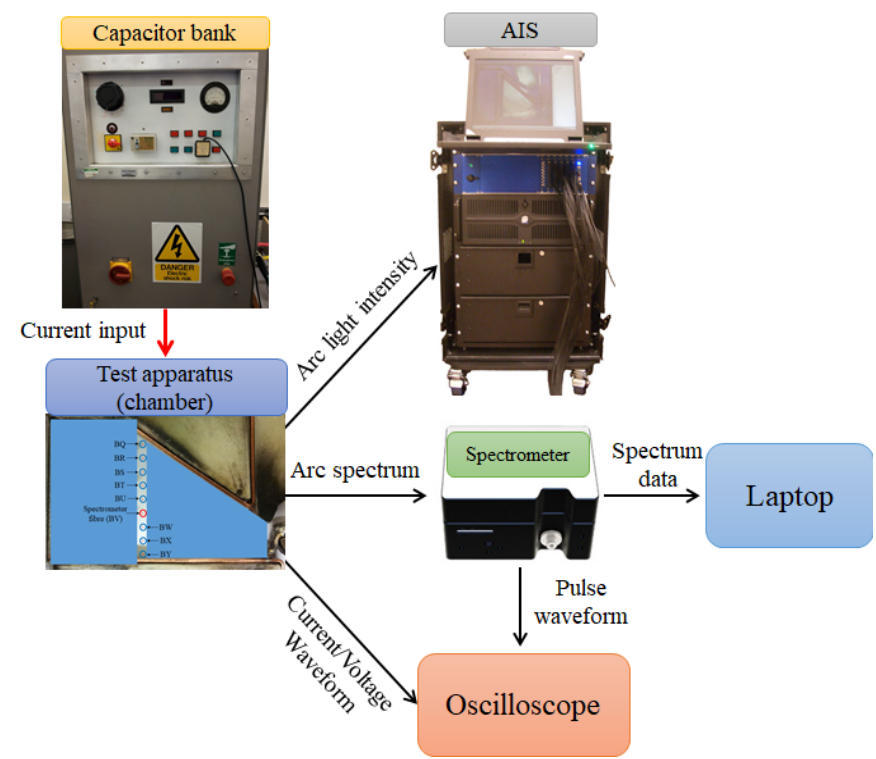

Fig. 1. The overall set-up for arc imaging and spectra measurement.

spectrometer generates a synchronisation pulse during the integration period. The synchronisation pulse signal is recorded by an oscilloscope along with the AIS trigger signal, current and voltage waveforms.

\section{B. Test Apparatus}

During the test, the arc intensity at the location of the spectrometer fibre cannot be directly measured by the AIS because it is occupied by the spectrometer fibre. The arc intensity at the spectrometer fibre is interpolated from the intensity data of the neighbouring fibres. The fibre positions are illustrated in Fig 2. BV is the location of the spectrometer fibre and other fibres are connected to the AIS. Fibres BU and BW are used to interpolate the arc intensity at the spectrometer fibre position, $\mathrm{BV}$.

The optical fibres are held in position by the fibre array block placed on the window of the enclosed chamber as shown in Fig. 3 (a). The fibre array block is made of black polyoxymethylene

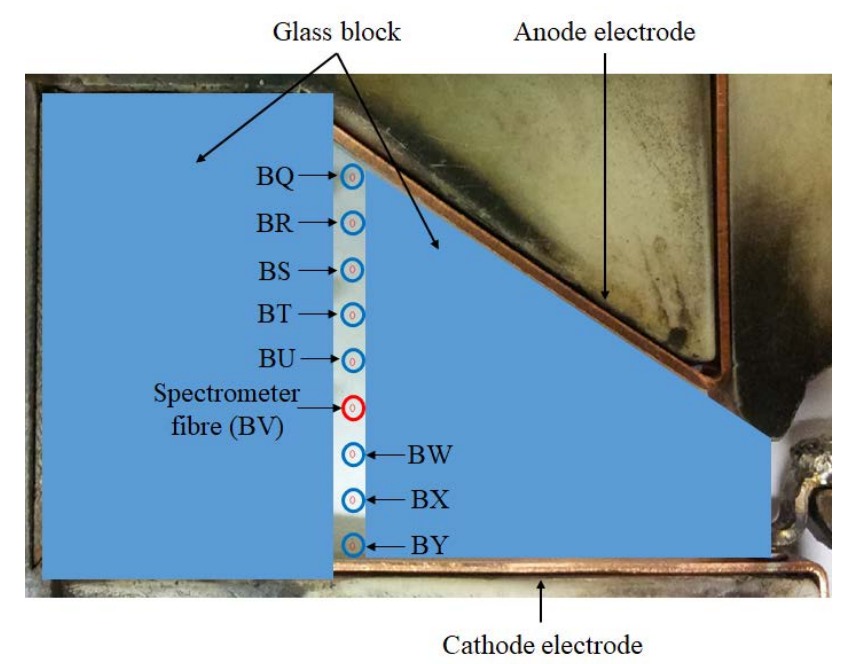

Fig. 2. The chamber and fibre locations of the test apparatus: BV is the location of the spectrometer fibre and others are the fibre locations for the arc images (light intensity measurement). 


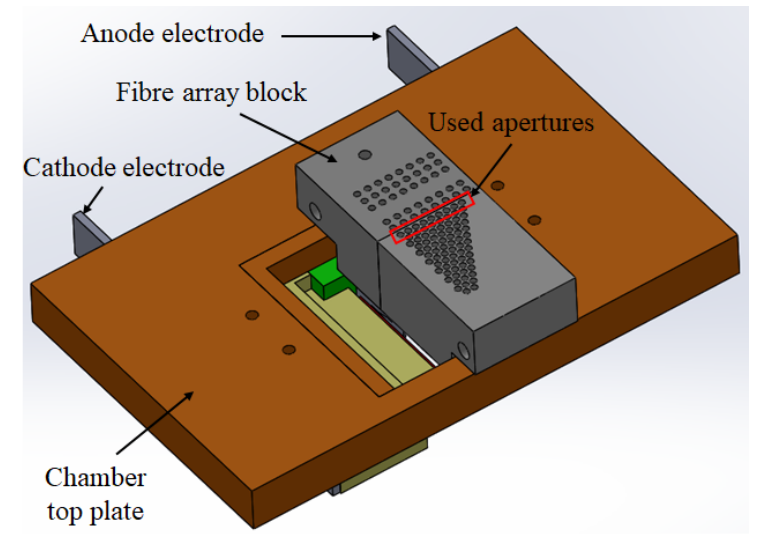

(a) Fibre array block of the test apparatus.

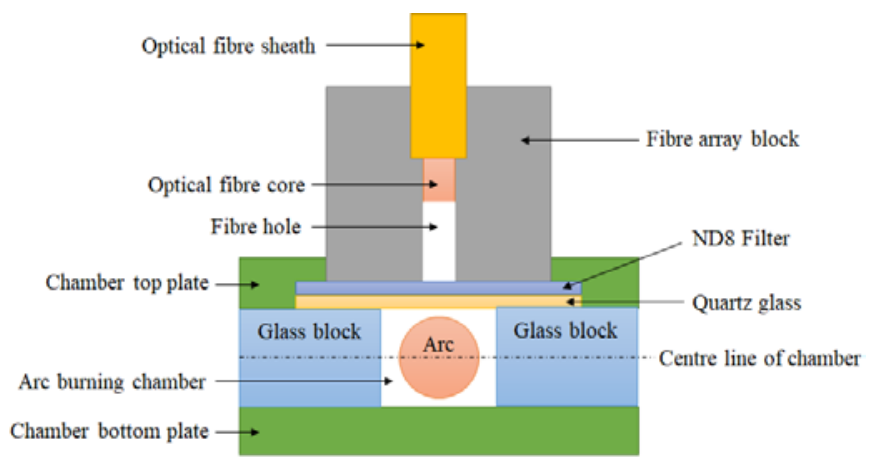

(b) Cross-section of the test apparatus.

Fig. 3. The structure of test apparatus.

TABLE I

SPECIFICATION OF THE AIS [3], [18].

\begin{tabular}{|c|c|}
\hline Item & Experimental value \\
\hline Sampling rate & $1 \mathrm{MHz}$ \\
\hline Number of optical fibres & 8 \\
\hline Light intensity resolution & 8 bit $(0-255)$ \\
\hline Fibre length & $2 \mathrm{~m}$ \\
\hline $\begin{array}{c}\text { Spectral sensitivity of } \\
\text { photodiode }\end{array}$ & $320-1060 \mathrm{~nm}$ \\
\hline
\end{tabular}

thermoplastic (Delrin) which is dimensionally stable, non-conductive, and optically opaque. Optical fibres are inserted into the apertures of the fibre array block so that each fibre has a view of a fixed position in the chamber. The field of view of each fibre has a $1.25 \mathrm{~mm}$ radius at the centreline of the chamber. Figure 3 (b) shows a cross-section of the fibre array block and enclosed chamber. To ensure that the arc light does not saturate the photodiode detectors, a neutral density optical filter (ND8) is placed between the array block and the quartz glass. This filter transmits about $12.5 \%$ of the full spectral range. The arc position is stabilised by ignition from a $0.2 \mathrm{~mm}$ diameter copper wire precisely positioned in the arc burning chamber. The arc burning chamber is created using two blocks of glass placed to make a narrow, enclosed space $(5 \mathrm{~mm} * 6 \mathrm{~mm}$ * $30 \mathrm{~mm}$ ), shown in the cross-section in Fig. 3 (b).
TABLE II

SPECIFICATION OF THE SPECTROMETER [19].

\begin{tabular}{|c|c|}
\hline Grating & 600 lines $/ \mathrm{mm}$ \\
\hline Entrance slit & $25 \mu \mathrm{m}$ \\
\hline Spectral range & $350-1000 \mathrm{~nm}$ \\
\hline Integration time $^{\mathrm{a}}$ & $30 \mu \mathrm{s}$ \\
\hline Acquisition rate & $\sim 4 \mathrm{kHz}{ }^{\mathrm{b}}$ \\
\hline
\end{tabular}

a Integration time is the time period that the detector is allowed to collect photons.

${ }^{\mathrm{b}}$ Frame refers to a single data set of spectra intensities measured during a $30 \mu \mathrm{s}$ integration time.

\section{Arc Imaging System (AIS)}

The half-cycle current is provided by a capacitor bank that is discharged through the copper wire to ignite the arc. The arc light is transmitted by $2 \mathrm{~m}$ optical fibres to the photodiode detectors of the AIS instrument. The photodiodes have a spectral response range from 320 to $1060 \mathrm{~nm}$. The AIS enables the tracking of the arc motion by capturing the arc light intensity inside the chamber sampled at $1 \mathrm{MHz}$ with and 8-bit resolution (256 levels). Table I shows the specification of the AIS used in this study [3], [18].

\section{Spectrometer}

The spectrometer (Ocean Insight, Ocean FX [19]) captures the light spectra from the stable arc in the enclosed chamber. The spectrometer specifications are summarised in Table II. Integration time is the time period when the detector is allowed

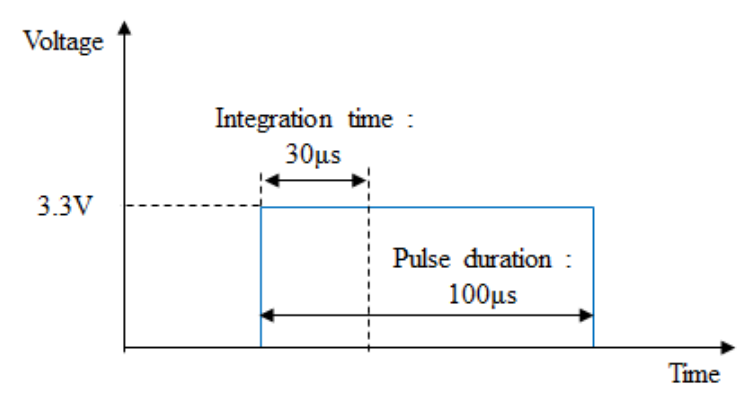

Fig. 4. Duration of the pulse waveform and integration time.

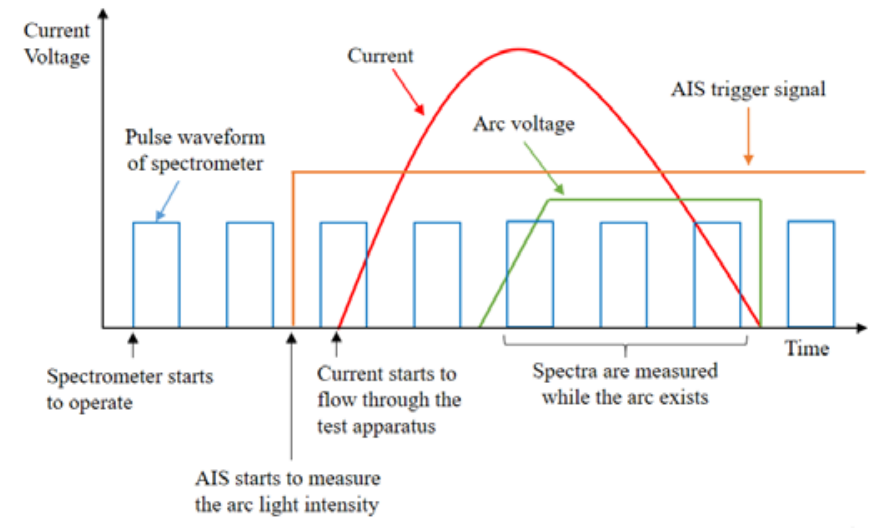

Fig. 5. Pulse, AIS trigger signal, current and arc voltage waveforms. 
to collect photons. Frame refers to a single data set of spectra intensities measured during the integration time. The integration time for one frame is $30 \mu$ s and the frames are captured at approximately $4 \mathrm{kHz}$. The 600 lines $/ \mathrm{mm}$ grating and the $25 \mu \mathrm{m}$ slit are used in the spectrometer with sensitivity in the wavelength range of $350 \sim 1000 \mathrm{~nm}$. The spectrometer generates pulse waveforms, $3.3 \mathrm{~V}$ with a duration of $100 \mu \mathrm{s}$. The timing of the spectrometer pulse and integration time of each frame is shown in Fig. 4. The start of each integration time is synchronised with the rising edge of each spectrometer pulse. To synchronise each spectra frame with the AIS data (including the arc current and voltage), the pulse waveforms from the spectrometer are recorded by an oscilloscope along with the AIS trigger signal, capacitor bank current, and arc voltage (electrode voltage). Figure 5 shows typical waveforms for the synchronisation pulse of the spectrometer, AIS trigger signal, current, and arc voltage.

\section{RESULTS AND DISCUSSION}

The arc temperature is calculated by the Boltzmann plot method from the $\mathrm{Cu}$ I spectra measured by the spectrometer. The values of arc temperature obtained in this study agree with other experimentally measured data within 10\% [15]. By comparing the arc temperature and light intensity measured by the AIS, their relationship is investigated.

\section{A. Cu I Lines of Emission Spectra}

Figure 6 shows the current, arc voltage, and pulse waveforms of the spectrometer while a peak current of 450 A flows through the test apparatus. A step in the arc voltage of around $25 \mathrm{~V}$ is observed at $1.22 \mathrm{~ms}$ suggesting the copper wire has ruptured due to ohmic heating. From $1.22 \mathrm{~ms}$ until the interruption of current, at $9.69 \mathrm{~ms}$, the arc is present in the chamber. During this period 36 spectra frames are collected and numbered from Frame 1 (collected at $1.22 \mathrm{~ms}$ ) to Frame 36 (collected at 9.69 $\mathrm{ms}$ ). During the initial phase of arcing from $1.22 \mathrm{~ms}$ (the position of the start of the arc ignition) to $2.53 \mathrm{~ms}$ (the position of the peak of arc voltage) the copper wire is ruptured and begins to evaporate. More $\mathrm{Cu}$ vapour is added as the wire is evaporated along its length. After $2.53 \mathrm{~ms}$, there is no wire remaining and the $\mathrm{Cu}$ gas is mixed with air. Distinct spectrum

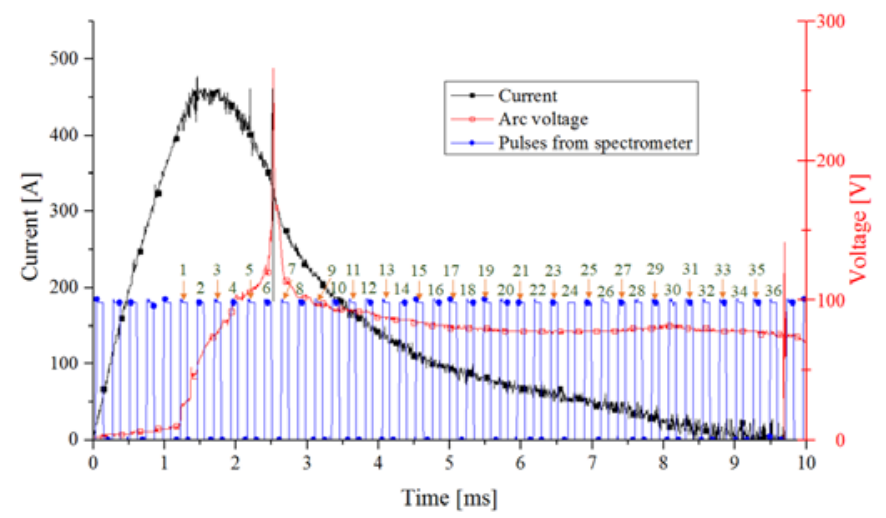

Fig. 6. Current, arc voltage and pulse waveforms for arc spectra measurement; the voltage of spectrometer pulse is $3.3 \mathrm{~V}$.

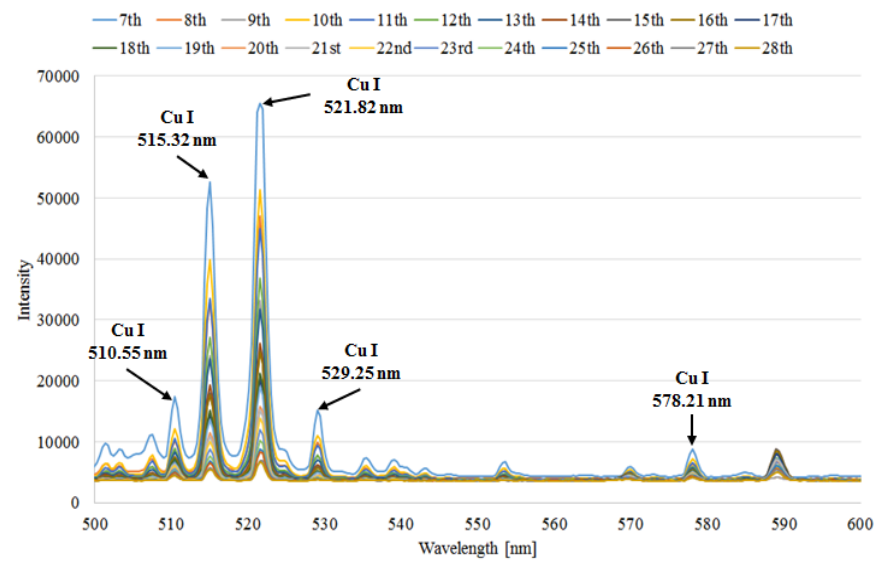

Fig. 7. Cu I spectrum lines of arc plasma from 500 to $600 \mathrm{~nm}$, measured from Frame 7 to 28 in Fig. 6; the spectrum intensity of Frame 7 reaches the saturated value of the spectrometer at $521.82 \mathrm{~nm}$.

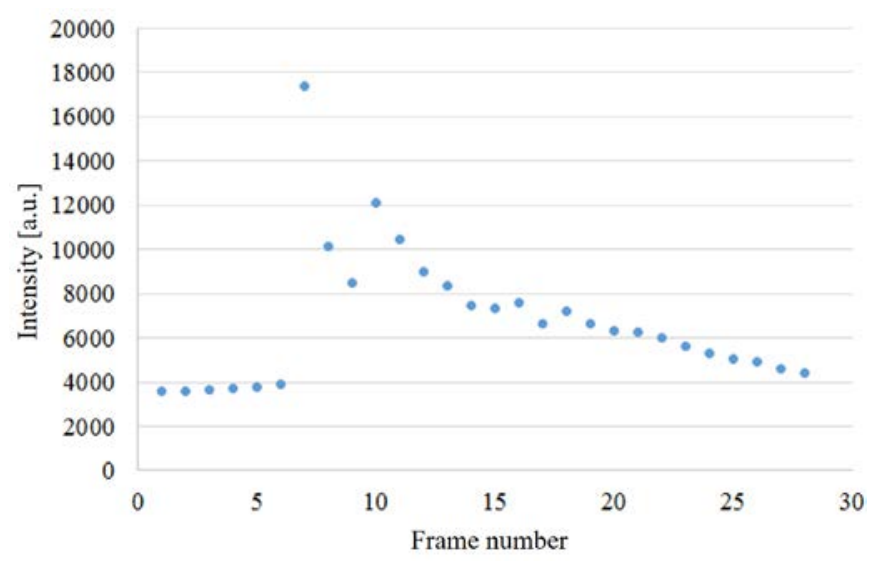

Fig. 8. Intensities of $\mathrm{Cu}$ I spectra at $510.55 \mathrm{~nm}$ measured from Frame 1 to 28 in Fig. 6.

lines are not observed in Frame 1 to Frame 6. This is expected as the wire has not yet evaporated at the precise position of the spectrometer fibre. From Frame 7 (collected at $2.53 \mathrm{~ms}$ ) to 28, the distinct $\mathrm{Cu}$ I spectrum lines are detected. From Frame 29 onwards (time $>7.75 \mathrm{~ms}$ ), the peaks of $\mathrm{Cu}$ I spectrum lines are too weak to evaluate the temperature due to the reduction in the current. The spectrum data from Frame 7 to 28 are used to calculate the arc temperature. Figure 7 shows these spectra at wavelengths between 500 and $600 \mathrm{~nm}$ and 5 distinct peaks of $\mathrm{Cu}$ I spectrum line are observed.

TABLE III

PARAMETERS OF CU I SPECTRUM [20].

\begin{tabular}{|c|c|c|c|}
\hline \multirow{3}{*}{ Spectrum } & $\begin{array}{c}\text { Wavelength } \\
{[\mathrm{nm}]}\end{array}$ & $\begin{array}{c}\text { Energy of upper state } \\
{[\mathrm{eV}]}\end{array}$ & $\begin{array}{c}\mathrm{gA}^{\mathrm{a}} \\
{\left[10^{8} \mathrm{~s}^{-1}\right]}\end{array}$ \\
\hline \multirow{5}{*}{$\mathrm{Cu}$ I } & 510.55 & 3.82 & 0.080 \\
\cline { 2 - 4 } & 515.32 & 6.19 & 2.4 \\
\cline { 2 - 4 } & 521.82 & 6.19 & 4.5 \\
\cline { 2 - 4 } & 529.25 & 7.74 & 0.87 \\
\cline { 2 - 4 } & 578.21 & 3.79 & 0.033 \\
\hline
\end{tabular}

${ }^{\mathrm{a}} \mathrm{g}$ and A refer to the statistical weight and transition probability of the upper level, respectively. 
Figure 8 shows the relative spectrum intensity at $510.55 \mathrm{~nm}$ from Frame 1 to 28. The highest intensity is measured in Frame 7 (2.53 ms) and it drops more than $40 \%$ by Frame 8 . This peak is expected as the $\mathrm{Cu}$ wire has been fully ruptured and vaporised, causing a peak in the pressure inside the chamber that rapidly decreases.

Each spectrum line has its own energy level, statistical weight, and transition probability at a specific wavelength as shown in Table III [20], and these parameters are used to evaluate the arc temperature by the Boltzmann plot method. In Frame 7, the spectrum intensity at $521.82 \mathrm{~nm}$ is saturated; therefore, only four spectrum intensities (the value at 510.55, 515.32, 529.25, and $578.21 \mathrm{~nm}$ ) are used for the arc temperature calculation.

\section{B. Calculation of Arc Temperature}

The arc temperature is estimated by the Boltzmann plot method. The Boltzmann plot method is widely used to evaluate arc temperature based on the relative intensities of the same species at a different wavelength [14], [21]. Under the assumption of the local thermal equilibrium (LTE) condition, the intensity ratio of two points of the spectrum line is given as,

$$
\frac{I_{1}}{I_{2}}=\frac{g_{1} A_{1} \lambda_{2}}{g_{2} A_{2} \lambda_{1}} \exp \left(-\frac{E_{1}-E_{2}}{k T}\right)
$$

where, $I_{1}$ and $I_{2}$ are the relative intensities of the emission spectrum, $A_{1}$ and $A_{2}$ are the transition probability (the probability per second that an electron de-exits from a specific upper state to a lower state, leading to photon emission), $g_{1}$ and $g_{2}$ are the statistical weights of the respective states, $E_{1}$ and $E_{2}$ are the energy levels, $k$ is the Boltzmann constant, and $T$ is the temperature in K. Tasking the logarithm of both sides of (1) to give (2)

$$
\ln \left(\frac{I_{1} \lambda_{1}}{g_{1} A_{1}}\right)-\ln \left(\frac{I_{2} \lambda_{2}}{g_{2} A_{2}}\right)=-\frac{E_{1}-E_{2}}{k T}+C
$$

where, $C$ is a constant. The temperature is obtained from the gradient of the $\ln (I \lambda / g A)$ against $E$ (the energy level) plot.

Figures 9 - 11 show the ND8 filter transmission rate, fibre attenuation, and spectrometer efficiency in a range of 500 to $600 \mathrm{~nm}$. It is seen that the characteristics of ND8 filter, fibre, and spectrometer are significantly varied with the wavelength; therefore, their characteristics are considered to obtain accurate relative spectrum intensities. The relative intensity of the arc spectrum is calculated based on the measured intensity (Fig. 7) and the characteristics of the optical filter, fibre, and spectrometer according to (3),

$$
I=i_{m} \cdot f(\text { filter, fibre, spectrometer }),
$$

where, $I$ is the corrected relative intensity, $i_{m}$ is the measured spectrum intensity, and f(filter, fibre, spectrometer) is the correction factor for the optical filter, fibre, and spectrometer influence. Based on (3), the corrected relative intensities of $\mathrm{Cu}$ I

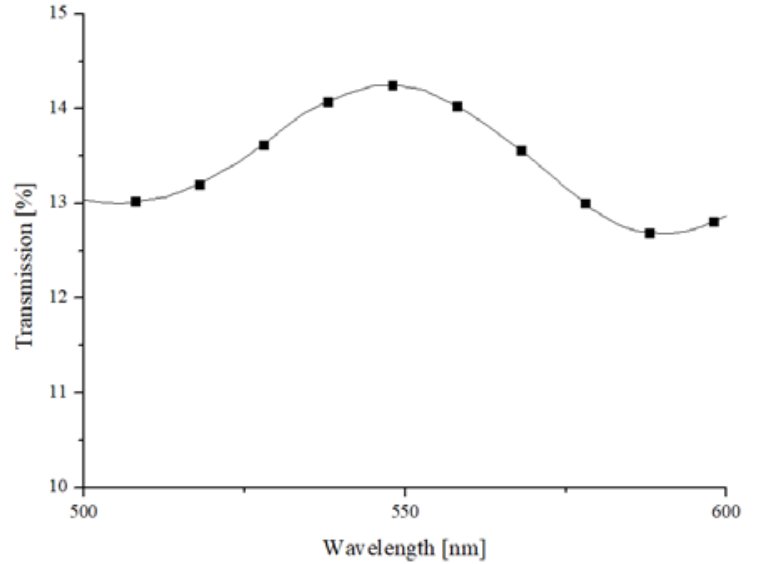

Fig. 9. Natural density (ND8) filter transmission rate in a range of 500 to 600 $\mathrm{nm}$ [22].

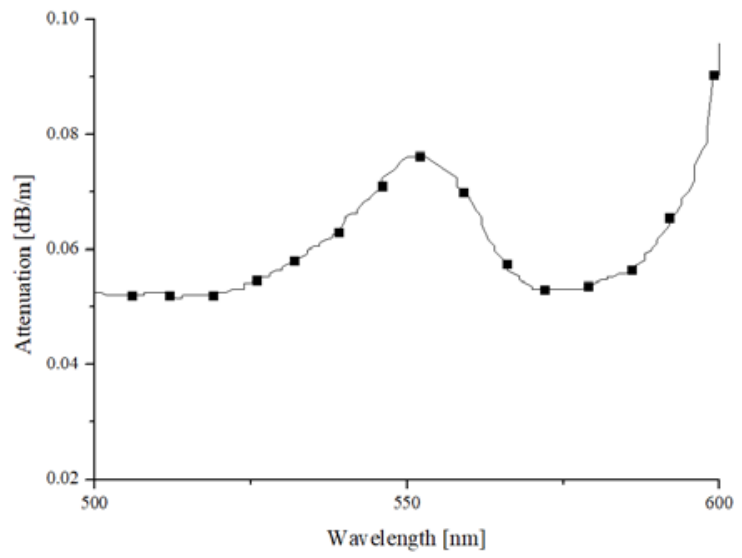

Fig. 10. Fibre attenuation in a range of 500 to $600 \mathrm{~nm}$ [23].

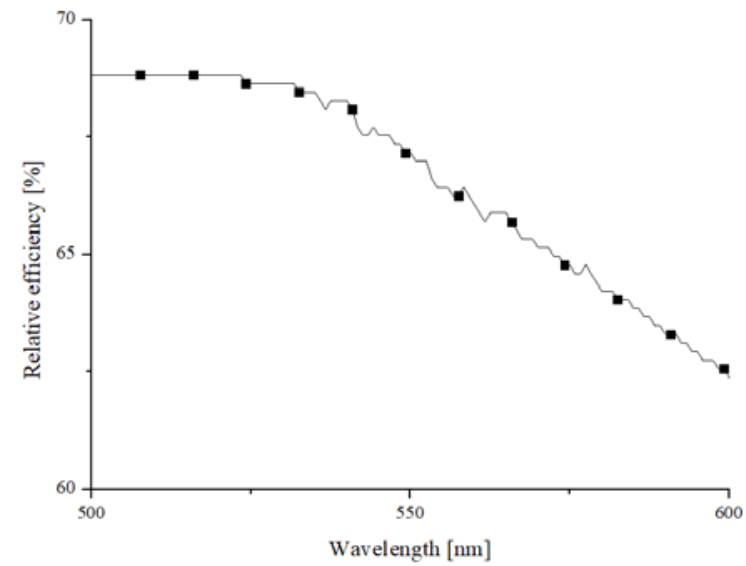

Fig. 11. Spectrometer efficiency in a range of 500 to $600 \mathrm{~nm}$; Ocean Insight provided the data.

spectrum in a range of 500 to $600 \mathrm{~nm}$ are calculated. To get the accurate temperature, the background intensity values (continuous radiation) are subtracted from the corrected relative intensities. This provides the peak relative intensities of $\mathrm{Cu} \mathrm{I}$ at 510.55, 515.32, 521.82, 529.25, and $578.21 \mathrm{~nm}$.

Table IV shows the peak relative intensities of Cu I spectra, $I_{p}$, $\ln (\lambda I / g A)$, the linear trend line, and calculated arc temperature for Frame 8, 10, 13, 16, and 18. The Boltzmann plot for the peak relative intensity values from the Frame 18 spectrum is shown in Fig. 12. The five spectrum line intensities are plotted with a line of best fit. The gradient of -0.91 corresponds to a temperature of $12792 \mathrm{~K}$. 
TABLE IV

CORRECTED RELATIVE PEAK INTENSITY OF CU I SPECTRUM AND CALCULATED TEMPERATURE.

\begin{tabular}{|c|c|c|c|c|c|}
\hline $\begin{array}{l}\text { Frame }{ }^{\mathrm{a}} \\
\text { (Time }^{\mathrm{b}} \text { ) }\end{array}$ & $\begin{array}{c}\text { Wavelength } \\
(\lambda) \\
{[\mathrm{nm}]} \\
\end{array}$ & \begin{tabular}{|c|} 
Peak relative \\
intensity ${ }^{\mathrm{c}}\left(I_{P}\right)$ \\
[a.u.]
\end{tabular} & $\ln \left(\lambda I_{p} / g A\right)$ & Slope $^{d}$ & $\begin{array}{c}\text { Temperature } \\
{[\mathrm{K}]}\end{array}$ \\
\hline \multirow{5}{*}{$\begin{array}{c}\text { Frame } 8 \\
(2.88 \mathrm{~ms})\end{array}$} & 510.55 & 79531 & 1.62 & \multirow{5}{*}{-0.69} & \multirow{5}{*}{16850} \\
\hline & 515.32 & 437239 & -0.063 & & \\
\hline & 521.82 & 636402 & -0.30 & & \\
\hline & 529.25 & 81022 & -0.71 & & \\
\hline & 578.21 & 41202 & 1.98 & & \\
\hline \multirow{5}{*}{$\begin{array}{l}\text { Frame } 10 \\
(3.35 \mathrm{~ms})\end{array}$} & 510.55 & 108242 & 1.93 & \multirow{5}{*}{-0.73} & \multirow{5}{*}{15832} \\
\hline & 515.32 & 537798 & 0.14 & & \\
\hline & 521.82 & 694256 & -0.22 & & \\
\hline & 529.25 & 95947 & -0.54 & & \\
\hline & 578.21 & 56274 & 2.29 & & \\
\hline \multirow{5}{*}{$\begin{array}{l}\text { Frame } 13 \\
(4.06 \mathrm{~ms})\end{array}$} & 510.55 & 64499 & 1.42 & \multirow{5}{*}{-0.77} & \multirow{5}{*}{15005} \\
\hline & 515.32 & 299084 & -0.44 & & \\
\hline & 521.82 & 415341 & -0.73 & & \\
\hline & 529.25 & 46438 & -1.27 & & \\
\hline & 578.21 & 33067 & 1.76 & & \\
\hline \multirow{5}{*}{$\begin{array}{l}\text { Frame } 16 \\
(4.77 \mathrm{~ms})\end{array}$} & 510.55 & 56532 & 1.28 & \multirow{5}{*}{-0.84} & \multirow{5}{*}{13797} \\
\hline & 515.32 & 213397 & -0.78 & & \\
\hline & 521.82 & 314188 & -1.01 & & \\
\hline & 529.25 & 27842 & -1.78 & & \\
\hline & 578.21 & 29888 & 1.66 & & \\
\hline \multirow{5}{*}{$\begin{array}{l}\text { Frame } 18 \\
(5.24 \mathrm{~ms})\end{array}$} & 510.55 & 52982 & 1.22 & \multirow{5}{*}{-0.91} & \multirow{5}{*}{12792} \\
\hline & 515.32 & 175999 & -0.97 & & \\
\hline & 521.82 & 262434 & -1.19 & & \\
\hline & 529.25 & 21985 & -2.0 & & \\
\hline & 578.21 & 27844 & 1.58 & & \\
\hline
\end{tabular}

${ }^{\mathrm{a}}$ The frame number corresponds with Fig. 6.

${ }^{\mathrm{b}}$ Time represents the starting instance of the integration time.

${ }^{\mathrm{c}}$ The peak relative intensity is obtained by considering the effects of filter transmission, fibre attenuation, spectrometer efficiency, and background intensity (continuous radiation).

${ }^{\mathrm{d}}$ Slope refers to the slope of the linear trend line among five points as shown in Fig. 12.

\section{Discussion}

The arc voltage and light intensity between $1.0 \mathrm{~ms}$ and $4.0 \mathrm{~ms}$ are shown for the lower 4 fibres in Fig. 13 and the upper 4 fibres in Fig. 14. In Fig. 13, the light intensity shows the arc ignition begins at fibre $\mathrm{BY}$ (the bottom of the closed chamber) and the $\mathrm{Cu}$ wire is evaporated along its length ( $\mathrm{BY} \rightarrow \mathrm{BX} \rightarrow \mathrm{BW} \rightarrow \mathrm{BU}$ ). As the arc length increases, the arc voltage also increases. After steadily increasing, the arc voltage peaks at $265 \mathrm{~V}$ at $2.53 \mathrm{~ms}$, closely synchronised with the peak in light intensity at fibres BQ, BR, BS, BT, and BU, in Fig. 14. This indicates the $\mathrm{Cu}$ wire is fully ruptured and vaporised at $2.53 \mathrm{~ms}$. A fully rupture of $\mathrm{Cu}$

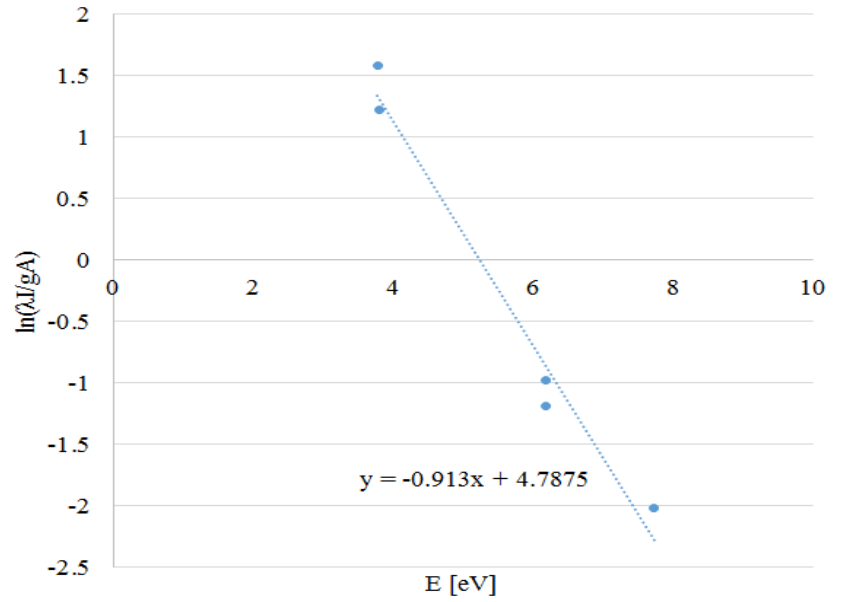

Fig. 12. Boltzmann plot of $\mathrm{Cu}$ I spectrum line at 510.55, 515.32, 521.82, 529.25, and $578.21 \mathrm{~nm}$ from Frame 18 (5.24 ms) in Table IV.

wire leads to a peak in the pressure inside the chamber, causing a highest arc voltage due to a squeezed arc column.

The light intensity data at fibres BU and BW are plotted against time in Fig. 15. Light intensities at fibres BU and BW

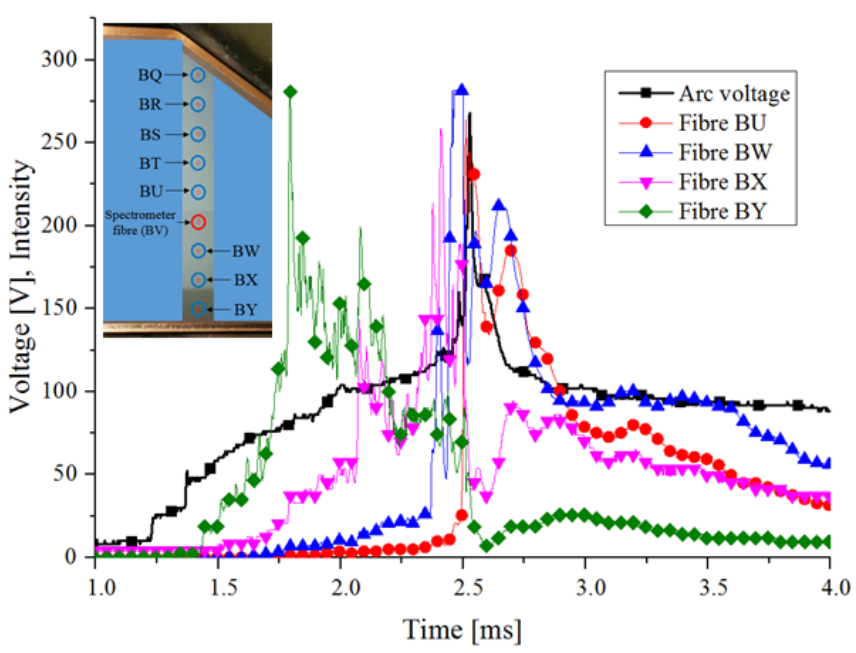

Fig. 13. Arc voltage and light intensities at fibre BU, BW, BX, and BY points in the chamber between $1.0 \mathrm{~ms}$ and $4.0 \mathrm{~ms}$.

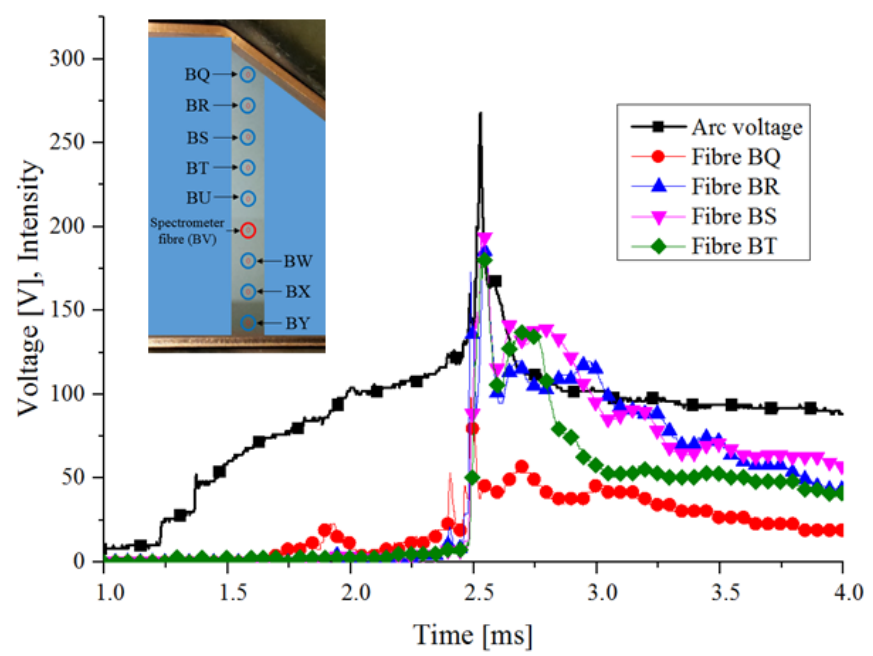

Fig. 14. Arc voltage and light intensity at fibre BQ, BR, BS, and BT points in the chamber between $1.0 \mathrm{~ms}$ and $4.0 \mathrm{~ms}$. 


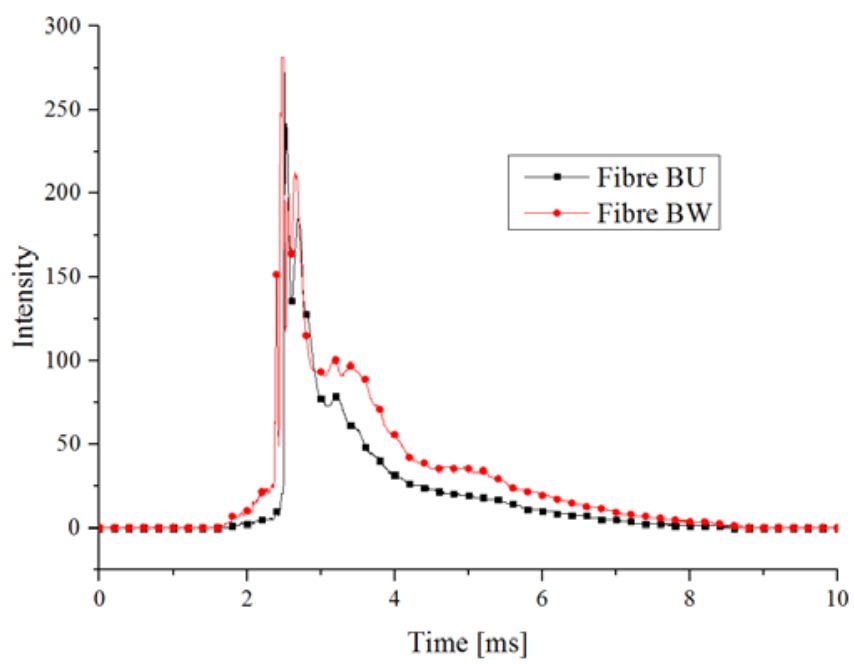

Fig. 15. Light intensity at fibre BU and BW.

fluctuate significantly in the early stage of arcing period (until $3.5 \mathrm{~ms})$. This variation can be attributed to the copper wire rupture and the relatively high pressure generated during the arc ignition process within a narrow enclosed chamber. From 3.5 ms (from Frame 11) the light intensity does not fluctuate significantly; therefore, we only use the AIS and spectrometer data from Frame 11 (the first frame of the stable arc period) to Frame 28 (the last frame of the distinct $\mathrm{Cu}$ I spectra) in Fig. 6 to investigate the relationship between the arc light intensity and temperature.

There is no light intensity data measured by the AIS from the spectrometer fibre position (BV) since the spectrometer is connected to it; however, the light intensity at position BV is derived by linear interpolation from adjacent fibres (BU and BW). Figure 16 shows the interpolated (AIS) light intensity at fibre BV and the calculated arc temperature from Frame 7 to 28. The (AIS) light intensity used is the maximum interpolated value at fibre BV during the $30 \mu$ s integration time of the spectrometer. After the unstable transient period (from ignition to $3.5 \mathrm{~ms}$ ) where the intensity of neighbouring fibre has significant fluctuation, the light intensity smoothly decreases as the arc temperature lowers.

The radiation power from the arc across all wavelength relates to the fourth power of temperature as below

$$
P_{r} \propto \sigma_{S B} T^{4},
$$

where, $P_{r}$ is the radiation emissive power, $\sigma_{S B}$ is the Stefan-Boltzmann constant, and $T$ is the temperature [13]. The photodiode provides a current proportional to the incident emissive power (the photodiodes used in the AIS have a 0.55 $\mathrm{A} / \mathrm{W}$ photosensitivity under the conditions of $25{ }^{\circ} \mathrm{C}$ temperature and $780 \mathrm{~nm}$ wavelength). Figure 17 shows the correlation between the fourth power of temperature and the interpolated light intensity based on the AIS data from optical fibres BU and BW during the stable arc period (from Frame 11 to Frame 28 in Fig. 6). The fourth power of temperature represents the radiation power from the arc. The light intensity

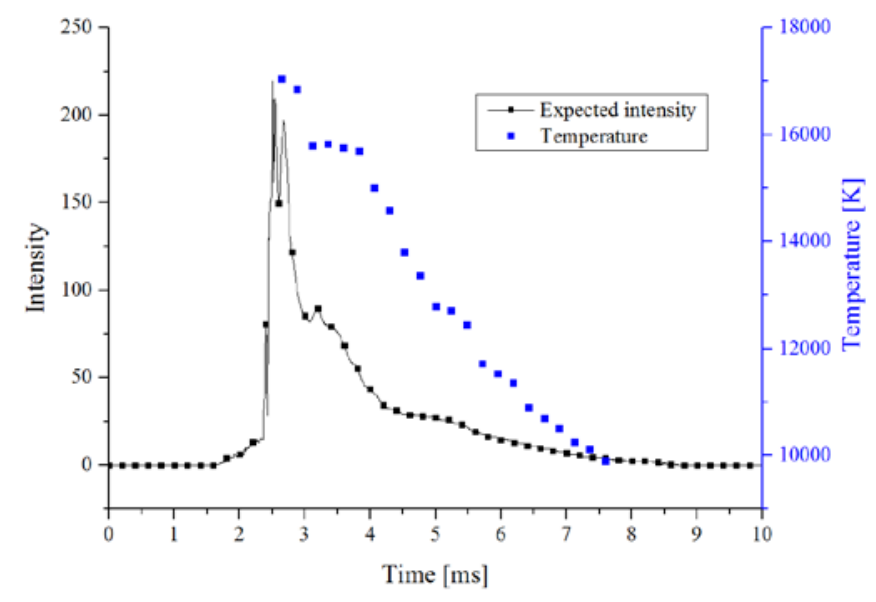

Fig. 16. Expected light intensity at fibre BV with arc temperature obtained by Boltzmann plot method from Frame 7 to 28: the intensity at BV is calculated as the average value of two neighbouring fibres (BU and $\mathrm{BW}$ ).

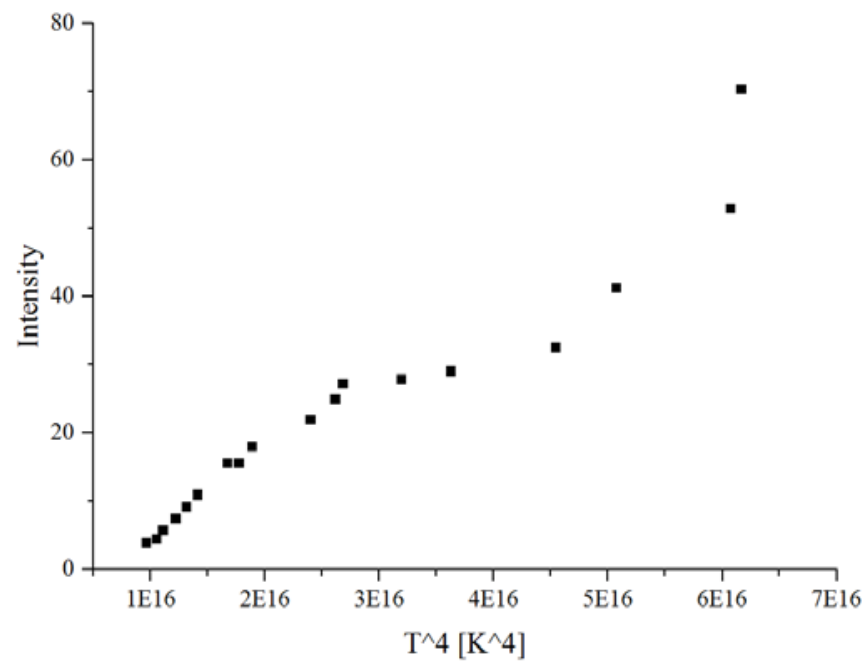

Fig. 17. Correlation between arc temperature (the fourth power of temperature) and expected light intensity at fibre BV; the intensity represents the maximum value of interpolated light intensity during the $30 \mu$ integration time.

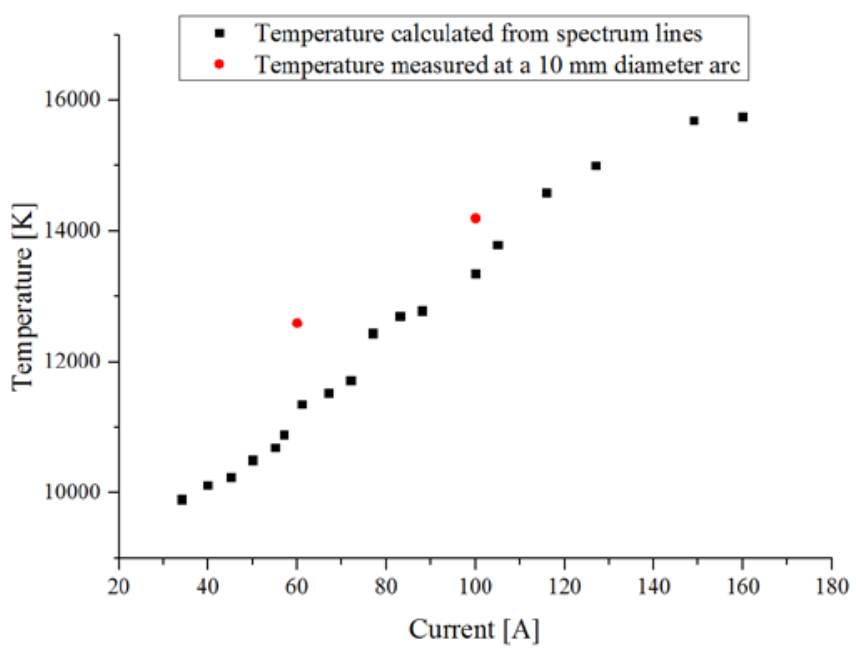

Fig. 18. Arc temperature depending on current; the current represents the maximum value of the current waveform during the $30 \mu$ s integration time, black squares are the values of arc temperature derived from Cu I spectra at fibre BV, red rounds are the arc temperature obtained by the shock wave technique in a $10 \mathrm{~mm}$ diameter chamber [15]. 


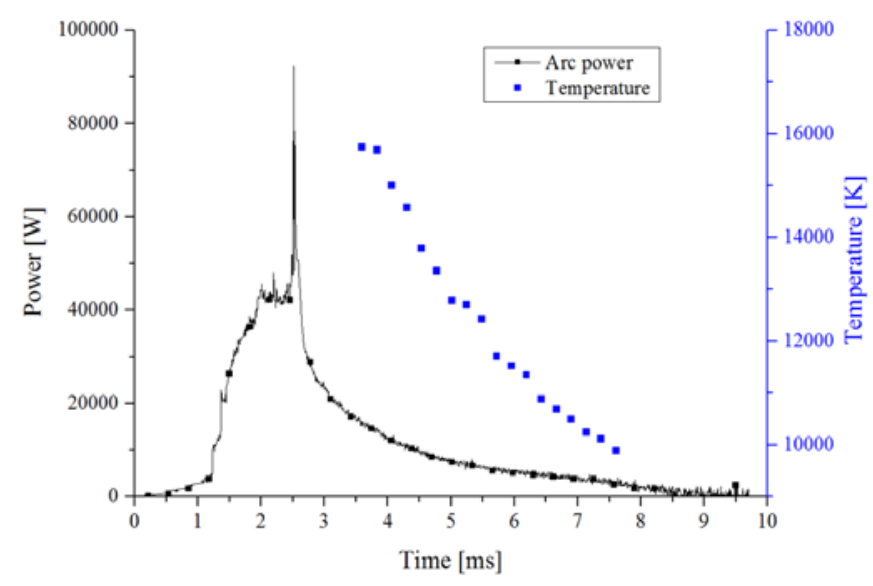

Fig. 19. Arc power and arc temperature: arc power calculated from the arc voltage and current (see Fig. 6).

strongly correlates with $\mathrm{T}^{4}$. The light intensity shows a linear trend with $\mathrm{T}^{4}$; increasing as the value of $\mathrm{T}^{4}$ increases. From this data it is shown the light intensity measured by the AIS is linked to the arc temperature as expressed in (4).

Figure 18 shows the relationship between the arc temperature and the measured current during the stable arc period (from Frame 11 to 28 in Fig. 6). It is observed that the arc temperature increases as the current increases. The current represents the maximum value of the current waveform in Fig. 6 during the 30 $\mu \mathrm{s}$ integration time. Black squares are the values of arc temperature derived from spectra data at fibre BV by Boltzmann plot method. Red circles indicate the arc temperatures obtained in a $10 \mathrm{~mm}$ diameter stabilized chamber by the shock wave technique where the temperature of the cylindrical air arc was reported as $12600 \mathrm{~K}$ at $60 \mathrm{~A}$ and 14200 $\mathrm{K}$ at 100 A current [15]. Using the Boltzmann plot method, this investigation calculates arc temperatures from the relative intensity of $\mathrm{Cu}$ I spectra of $11364 \mathrm{~K}$ at $61 \mathrm{~A}$ and $13362 \mathrm{~K}$ at 100 $\mathrm{A}$ at the spectrum fibre location (BV). The calculated temperature, therefore, shows a good agreement with those previously reported. If the arc temperature from [14] and [16] (7000 K at 3.3 A and $21500 \mathrm{~K}$ at $1100 \mathrm{~A}$ ) are plotted in Fig. 18, it is shown that there is not a simple linear relationship between arc temperature and current. However, it is noted that over a wider range of current the relationship is more likely to be a logarithmic curve as the increase in arc temperature is much greater from $3.3 \mathrm{~A}$ to $160 \mathrm{~A}$ than from $160 \mathrm{~A}$ to $1100 \mathrm{~A}$.

Figure 19 shows the arc power (obtained from the arc voltage and current shown in Fig. 6) and arc temperature during the stable arc period (from Frame 11 to 28 in Fig. 6). It is seen that the temperature drops as the arc power decreases; ohmic heating from arc power is regarded as the main factor related to the arc temperature. In addition, it can be said that the arc power in this test is mainly determined by the current since the arc voltage is almost constant during the stable arc period as shown in Fig. 6.

To confirm the findings shown in Fig. 16 - 19, the investigation was repeated under the same conditions. The results of the second experiment during the stable arc period are summarised in Table V. The results show the same trend as the first experiment with arc temperature increasing with the
TABLE V

RESULTS OF THE SECOND TEST.

\begin{tabular}{|c|c|c|c|}
\hline $\begin{array}{c}\text { Current } \\
{[\mathrm{A}]}\end{array}$ & $\begin{array}{c}\text { Arc Power } \\
{[\mathrm{W}]}\end{array}$ & $\begin{array}{c}\text { Temperature }^{\mathrm{b}} \\
{[\mathrm{K}]}\end{array}$ & Intensity $^{\mathrm{c}}$ \\
\hline 100 & 10000 & 13405 & 30 \\
\hline 72 & 6696 & 13140 & 19 \\
\hline 55 & 5115 & 12631 & 9 \\
\hline 45 & 4095 & 12273 & 4 \\
\hline 39 & 3549 & 11314 & 1.2 \\
\hline
\end{tabular}

${ }^{a}$ The current represents the maximum value of the current waveform during the $30 \mu$ s integration time.

${ }^{\mathrm{b}}$ The temperature is obtained from the Boltzmann plot method.

${ }^{\mathrm{c}}$ The intensity represents the maximum value of interpolated light intensity during the $30 \mu$ s integration time.

current or arc power. Significantly, the light intensity is again correlated with the fourth power of arc temperature.

It is concluded that the arc images from the AIS are directly related to the arc temperature. The higher arc current generates the greater arc power; then, the ohmic heating from the arc power leads to an increase in the arc temperature. The higher arc temperature results in the greater output current of AIS photodiodes, which is proportional to the radiation emissive power from the arc.

\section{CONCLUSION}

In this paper, an experimental investigation into the relationship between light intensity and temperature of the air arc is described. The following conclusions are drawn.

1) The arc light intensity measured by an Arc Imaging System (AIS) is directly related to the arc temperature, with the correlation between the fourth power of temperature and the light intensity following a linear trend.

2) As the arc current increases, the arc temperature increases due to ohmic heating from arc power. There is not a simple linear relationship between arc temperature and current; however, it is observed that the arc temperature is proportional to the logarithm of the arc current.

\section{REFERENCES}

[1] J. W. McBride and P. M. Weaver, "Review of arcing phenomena in low voltage current limiting circuit breakers," IEE Proc.-Sci. Meas. Technol., vol. 148, no. 1, pp. 1-7, Jan. 2001.

[2] D. Shin, I. O. Golosnoy, and J. W. McBride, "Experimental study of re-ignition evaluators in low voltage switching devices," IEEE Trans. Components Packag. Manuf. Technol., vol. 8, no. 6, PP. 950-957, Mar. 2018.

[3] J. W. McBride, "The verification of a computational model of arc motion using an arc imaging system”, Proceedings of the $22^{\text {nd }}$ International Conference on Gas Discharge and their applications, Serbia, 2018, pp. 27-31.

[4] R. Ma, M. Rong, F. Yang, Y. Wu, H. Sun, D. Yuan, H. Wang, and C. Niu, "Investigation on arc behavior during arc motion in air DC circuit breaker,” IEEE Trans. Plasma Sci., vol. 41, no. 9, pp. 2551-2560, 2013.

[5] D. Cajal, A. Laurent, F. Gary, M. Mercier, and S. Servant, "A study of the various phases of the break in a low-voltage circuit breaker thanks to the 
magnetic camera,” J. Phys. D. Appl. Phys., vol. 32, no. 10, pp. 1130-1135, May. 1999.

[6] J. W. McBride, A. Balestrero, L. Ghezzi, G. Tribulato, and K. J. Cross, "Optical fiber imaging for high speed plasma motion diagnostics: applied to low voltage circuit breakers" Review of Scientific Instruments, 81, (5), 055109-[6pp], 2010.

[7] J. W. McBride, K. Pechrach, and P. M. Weaver, "Arc root commutation from moving contacts in low voltage devices," IEEE Trans. Components Packag. Technol., vol. 24, no. 3, pp. 331-336, 2001.

[8] J. W. McBride, K. Pechrach, and P. M. Weaver, "Arc motion and gas flow in current limiting circuit breakers operating with a low contact switching velocity," IEEE Trans. Components Packag. Technol., vol. 25, no. 3, pp. 427-433, 2002.

[9] J. W. McBride, P. M. Weaver, and P. A. Jeffery, "Arc root mobility during contact opening at high current," IEEE Trans. components, Packag. Manuf. Technol. Part A, vol. 21, no. 1, pp. 61-67, 1998.

[10] D. Chen, R. Dai, and X. Li, "Experimental investigation on the arc motion with different configurations of quenching chamber in AC contactor," IEICE Trans. Electron., vol. E89-C, no. 8, pp. 1201-1205, Aug. 2006.

[11] D. Shin, I. O. Golosnoy, and J. W. McBride, "Development of switching performance evaluator and arc modelling tool for low-voltage switching devices," COMPEL-Int. J. Comput. Math. Elect. Electron. Eng., vol. 37 no. 6, pp. 1943-1957, Nov. 2018.

[12] D. Shin, J. W. McBride, and I. O. Golosnoy, "Arc modelling to predict arc extinction in low-voltage switching devices," in Proc. 64th IEEE Holm Conf. Elect. Contacts, USA, Oct. 2018.

[13] R. Siegel and J. R. Howell, Thermal radiation heat transfer, 3rd edition, Washington: Hemisphere publishing corporation, 1992. pp. 11-46.

[14] M. Takeuchi and T. Kubono, "A spectroscopic detecting system for measuring the temperature distribution of silver breaking arc using a CCD color camera,” IEEE Trans. Instrum. Meas., vol. 48, no. 3, pp. 678-683, 1999.

[15] G. R. Jones, G. H. Freeman, and H. Edels, "Transient temperature distributions in cylindrical arc columns following abrupt current changes,” J. Phys. D Appl. Phys., vol. 4, pp. 236-245, 1971.

[16] P. G. Slade and E. Schulz-Gulde, "Spectroscopic analysis of high-current free-burning ac arcs between copper contacts in argon and air," J. Appl. Phys., vol. 44, no. 1, pp. 157-162, 1973.

[17] Ocean Insight, "OceanView." [Online]. Available: https://www.oceaninsight.com/products/software/acquisition-and-analys is/oceanview/. [Accessed: 22-Mar-2020].

[18] TaiCaan Technologies, "Arc imager." [Online]. Available: https://www.taicaan.com/?p=433. [Accessed: 23-Mar-2020].

[19] Ocean Insight, “Ocean FX Spectrometers.” [Online]. Available: https://www.oceaninsight.com/products/spectrometers/high-speed-acqui sition/ocean-fx/. [Accessed: 23-Mar-2020].

[20] NIST, “NIST Atomic Spectra Database Lines Data.” [Online]. Available: https://physics.nist.gov/cgi-bin/ASD/lines1.pl?spectra=Cu+I\&limits_typ e=0\&low_w=400\&upp_w=600\&unit $=1 \&$ submit $=$ Retrieve+Data\&de $=0$ $\&$ format $=0$ \&line_out $=3 \&$ en_unit $=1 \&$ output $=0$ \&bibrefs $=1 \&$ page_size $=$ $15 \&$ show_obs_wl $=1 \&$ show_calc_wl $=1 \& u n c$ out $=1 \&$ order_out $=0 \&$ max _low_enrg $=\&$ show_av $=2 \&$ max_upp_enrg $=\&$ tsb_value $=0 \&$ min_str $=\& A$ _out $=1 \&$ intens_out $=$ on\&max_str $=\&$ allowed_out $=1 \&$ forbid_out $=1 \& \mathrm{~min}$ _accur=\&min_intens=\&conf_out $=$ on \&term_out $=$ on\&enrg_out $=$ on \&J_o ut $=$ on. [Accessed: 10-Feb-2018].

[21] J. Tang, D. Zuo, Z. Jiu, and Z. Cheng, "Spectral property investigation of air plasma generated by pulsed $\mathrm{CO}_{2}$ laser," IEEE Trans. Plasma Sci., vol. 39, no. 4, pp. 1114-1119, Apr. 2011.

[22] Polytec, "Neutral Density Filters." [Online]. Available: https://www.polytec.com/eu/machine-vision/products/optical-filters/neut ral-density-filters/. [Accessed: 20-Mar-2020].

[23] Farnell, "FDPF 4001 EH - Fiber Optic Cable, Polymer, Simplex, Plastic Optical." [Online]. Available: http://uk.farnell.com/fibre-data/fdpf-4001-eh/fibre-polymer-1-core-20mreel/dp/1208838?st=Polymer Fibre Optic Cable. [Accessed: 20-Mar-2020].

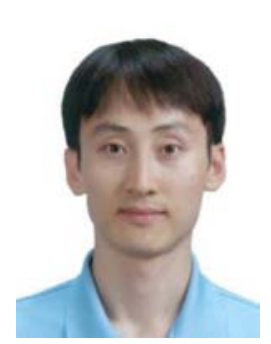

Dongkyu Shin received the B.Eng. degree in electrical engineering from Hanyang University, South Korea, in 2004, the M.Eng. degree in electrical engineering from Seoul National University, South Korea, in 2006, and the Ph.D. degree at the Electronics and Electrical Engineering Research Group, University of Southampton, U.K, in 2018. Now, he is a senior researcher in Hyundai Electric \& Energy system.

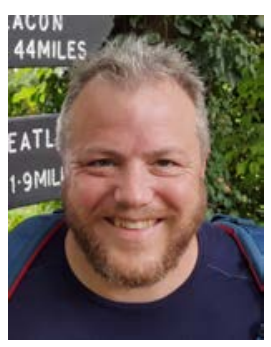

Thomas G. Bull received the B.Eng degree in Mechanical Engineering in 2015 and Ph.D. degree in 2020 from the University of Southampton. His expertise includes optical metrology and plasma arc imaging. He is currently a senior research fellow in the Mechatronics Research Group with research interests in MEMS switch contact wear.

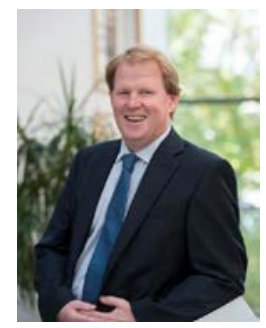

John W. McBride is the head of the Mechatronics research group, in Mechanical Engineering at the University of Southampton, UK. He was previously the CEO/provost of the University of Southampton-Malaysia Campus, Johor Bahru, Malaysia. He is an expert in electrical contact physics, arcing devices and surface metrology. He has authored over 300 papers, and holds three patents. 